\title{
Health of School-Aged Children in 11+ Hours of Center-Based Care
}

\author{
Tokie Anme ${ }^{1}$, Ryoji Shinohara ${ }^{1}$, Yuka Sugisawa ${ }^{1}$, Lian Tong ${ }^{1}$, Emiko Tanaka ${ }^{1}$, \\ Etsuko Tomisaki ${ }^{1}$, Taeko Watanabe ${ }^{1}$, Kentaro Tokutake ${ }^{1}$, Yukiko Motizuki ${ }^{1}$, \\ Hisako Matsumoto ${ }^{1}$, Chihiro Sugita ${ }^{1}$, Uma Segal ${ }^{2}$ \\ ${ }^{1}$ Graduate School of Comprehensive Human Sciences, University of Tsukuba, Tsukuba, Japan \\ ${ }^{2}$ School of Social Work, University of Missouri, St. Louis, USA \\ Email: anmet@md.tsukuba.ac.jp
}

Received March 18 ${ }^{\text {th }}$, 2012; revised April 12 ${ }^{\text {th }}$, 2012; accepted April $28^{\text {th }}, 2012$

\begin{abstract}
With increasing numbers of women joining the evening/nighttime and extended-hour workforce, there is a need for quality childcare during these hours. This project, conducted in Japan, sought to compare the effects of expanded child-care on the health of 271 school-aged children. Parents completed a survey on the childrearing environment at home, their feelings of self-efficacy, and the presence of support for childcare; and childcare professionals evaluated the development of these school-aged children. Children responded to questions regarding their health. Results of the multiple regression analysis indicate that factors in the home environment, not length of time in center-based care, explained health risks at school age.
\end{abstract}

Keywords: Health; Child-Care; Cohort Study

\section{Introduction}

Demands for the expansion of center-based child night and extended-hour care have dramatically increased with the rising numbers of working mothers in Japan. High-quality centerbased night care is essential to provide a safe and comfortable environment for children whose parents are employed in occupations that require long hours including evening and night shifts. Sixty-one authorized night care facilities, centers that are licensed by the national government as meeting quality care standards, have been established since 1981, after the several highly publicized involuntary homicides (cases of neglectful death) in the existing low-quality "Baby Hotels". Baby Hotels are facilities that continue to exist in Japan and that provide childcare services 24 hours-a-day for children from birth to seven years of age. With the continued shortage of authorized facilities, over 120,000 children use non-authorized, sub-standard Baby Hotels (Anme \& Segal, 2003, 2004). Governmental authorization standards are high, including many criteria including child-to-professional ratios (three babies to one nationally licensed professional), credentialling (licensed child care professionals and nurses), adequacy of physical environment (space, facilities, safety assurance) and sound management (budget, accountability, oversight).

The community health program that allows visiting nurses to provide preventative care for children in the home ceases as children enter the formal educational system, and primary schools experience a growing problem with increasing numbers of students with rising health concerns. Japanese children can be in child care from the ages 4 months to six years, the period during which they receive home visits from community nurses. They attend primary school (grades one to six) from seven years of age to twelve yeas. After six years in primary school, all children proceed to junior high school for another three years. Over $96 \%$ of these children go on to senior high shool for three more years, and 2006 census reports indicate that $76 \%$ children get higher education at a university or college following high school. It is essential that the health of these children be assessed to prevent health decline and to promote health for children in the school system.

Longitudinal research from the United Kingdom (1958-2007), and others, indicates the importance of the child environment during the toddler years in predicting later development (Shoon, 2006; Shoon \& Parson, 2002; Sacker, 2002; Salmela-Aro, 2005). The quality of care must be considered carefully if the effects of early childcare are to be understood [National Institute of Child Health and Human Development (NICHD), 1999a]. Children from higher-quality centers have been found to be less anxious and have less problematic transitions to school. However, in another longitudinal study, such positive effects of high quality center care facilities were not discernible among all children sampled at age 13 years (Andersson, 1992). NICHD (2001, 2002a) further found that the quality of maternal caregiving was the strongest predictor of development but that the quality of nonmaternal caregiving was also associated with children's development. Contrary to the NICHD's expectations, however, family risk factors were the strongest predictors of behavior problems, prosocial behavior, and langauge skills in another longitudinal study, but there was limited evidence that child care experiences moderated the negative associations between family risk and the child outcomes under investigation (NICHD, 2002b).

The NICHD (2003) and Langlois and Liben (2003) arrived at three conclusions: 1) the cumulative quantity of child care during the first four years of life predicts some problematic behaviors of children between ages 4.5 and 5 years, but these behaviors were corroborated by reports of parents and teachers, 
not with observed behaviors and were usually low to moderate, not large; 2) maternal sensitivity and family income were stronger predictors than quantity of care; and 3) the problem behaviors indicated were not at clinical levels.

Watamura et al. (2003) reported on some physiological correlates of child care, suggesting that toddlers in nonparental care may experience more stress by the afternoon hours than do those who are in maternal care. Effects of nonparental care may be mitigated by the quality of peer interaction they experience. Lamb (1996) reviewed the literature on the effects of nonparental care on children a decade ago and found that evidence was inconclusive and that nonparental care does not necessarily have either positive or detrimental effects on infants and children. The quality of the relationship between the care provider and the child substantially affects develoment. The findings of three different studies, one in Australia, another in Israel, and a third in the United States, were discussed by Love et al. (2003) to highlight that quality of care, rather than quantity, was a better predictor of children's outcomes, and in fact, when children are in non parental child care, parents compensate by increasing the intensity and amount of attention they devote to their children when they are together (Ahnert et al., 2003). On a different note, Crockenberg (2003) suggests that is not only the quality and quantity of care a child receives (either parental or nonparental) but also a child's temperatment and gender, including its tolerance for stress, that influence its development.

As the literature citations indicate, much of the study of child development in light of center-based child care has occurred in Western countries. Less is known about it in other countries such as Japan. Furthermore, traditionally, in Western countries, children are placed in nonparental care for between eight and ten hours during the workday. Despite the need for child care for children after 6:00 pm, there are few, if any, facilities that provide this service in most nations. Japan has responded to the need of working mothers, many of whom work long hours or during the nighttime hours, by establishing governmentally authorized night care facilities. This formalization of centerbased night care is rare in nations outside Japan. Even in Japan, few studies have assessed the influence of center-based night care on child development (Anme, 1998). This study sought to identify correlations between 1) extended-hour center-based, including nighttime care and school children's health; and 2) the childrearing environment provided by parents and children's health at when they are at school age.

\section{Methods}

\section{Setting and Sample}

All authorized child-night-care centers and attached childday-care facilities across Japan participated in the study at when the children were toddler-aged. Centers unauthorized by the government were excluded as they often do not cooperate with external investigators. The subjects were all parents and service providers in the authorized facilities. Parents were surveyed regarding the home environment, and service providers evaluated the development of each child in the facility. The baseline return rate was $74.6 \%$ (1957 between the ages of $0-6$ years) both for parents and service providers. Of these, 271 children from 22 authorized child care, participated in the survey at school age. Several families had moved their children from the 22 facilities that did participate; this is not unusual as parents often move residences for a variety of reasons. Parents and caregivers of children with disabilities were excluded from this second analysis as the needs and outcome measures of children with disabilities differed substantially from those of children without disabilities. The final usable set of follow-up responses was 271; children were between the ages of three to six years old at the time of the first study and were currently between the ages of seven and eleven. The usable responses were substantially lower than would have been preferred, yet sufficiently large to provide some meaningful findings.

Table 1 provides the gender and grade enrollment of the subject population. The distribution of boys, 123 (45.4\%), and girls, 148 (54.6\%), was fairly even. The largest number of children was in first grade (35.0\%), followed by those second (28.4\%) and third (17.0\%) grades.

Table 1.

Demographic background.

\begin{tabular}{|c|c|c|}
\hline Items & $\mathrm{N}$ & $\%$ \\
\hline \multicolumn{3}{|l|}{ Gender } \\
\hline Male & 123 & 45.4 \\
\hline Female & 148 & 54.6 \\
\hline \multicolumn{3}{|l|}{ Grade in school } \\
\hline First & 95 & 35.0 \\
\hline Second & 77 & 28.4 \\
\hline Third & 46 & 17.0 \\
\hline Forth & 29 & 10.7 \\
\hline Fifth & 24 & 8.9 \\
\hline \multicolumn{3}{|l|}{ Family type } \\
\hline \multicolumn{3}{|l|}{ Nuclear family } \\
\hline Parents & 184 & 67.9 \\
\hline Mother only & 43 & 15.9 \\
\hline Father only & 2 & 0.7 \\
\hline \multicolumn{3}{|l|}{ Extended family } \\
\hline Parents, grandparents & 25 & 9.2 \\
\hline Mother, grandparent & 9 & 3.3 \\
\hline Father, grandparent & 0 & 0.0 \\
\hline Other & 8 & 3.0 \\
\hline \multicolumn{3}{|l|}{ Siblings } \\
\hline Yes & 176 & 64.9 \\
\hline No & 95 & 35.1 \\
\hline \multicolumn{3}{|l|}{ Quantity of child care } \\
\hline 11 hours or more & 146 & 53.9 \\
\hline Less than 11 hours & 125 & 46.1 \\
\hline \multicolumn{3}{|l|}{ Respondent } \\
\hline Mother & 254 & 93.7 \\
\hline Father & 13 & 4.8 \\
\hline N.A. & 4 & 1.5 \\
\hline Total & 271 & 100.0 \\
\hline
\end{tabular}




\section{Overview of Measures}

Indicators of child-care quantity (length of time in care), stability (regularity of attendance), and type (normal vs long hours) along with measures of family background [socioeconomic status (determined by the requirement to pay income tax), family composition], the child's demographic characteristics, and child adaptation to center-based care (willingness to go to center-based care) were obtained from questionnaires completed by the parents responsible for the children in the first six years of their lives. Parents completed Japanese versions of questionnaires on the child-rearing environment (HOME, Caldwell \& Bradley, 1984, J-HOME, Anme, 1991, 1996) and on selfefficacy and support for childcare (Anme, 1995). Self-efficacy was evaluated by parental response on the item "I am convinced my capability to provide quality childcare". Support for childcare was determined by whether the parent reported assistance from a spouse or others.

Childcare professionals evaluated children's social competence, communication, and development in vocabulary/motor/ intelligence for each child from 2000 to 2005 using developmental scales (Anme, 2006). This scale was standardized in Japan and revealed that $10 \%$ of children in the Japanese population were below the normal range of age-appropriate cognitive development.

The social competence subscale includes items such as, "drinks from cup without assistance" at 11 months and, "able to change clothes" at 56 months. The communication subscale includes items such as, "smiles in response to caregiver's voice" at 4 months, "takes a particular role in playing 'house", at 36 month, etc. The vocabulary subscale includes "is able to say at least one word" at 12 months, and "follows story telling" at 60 months, etc. The motor subscale includes "is able to walk without assistance" at 14 months, "is able to draw an ' $\mathrm{X}$ '” at 45 month, etc. The intelligence subscale includes "understands 'eyes', 'mouth', 'nose' etc." at 21 month and can "count to three" at 42 months.

All childcare professionals, already qualified in child development, were provided with a minimum of eight hours of training to translate children's development into the measures indicated on the child development scale. These variables, selected to be consistent with earlier studies by the NICHD (1999a), were then used to explore the relationship between length of care and child development.

The two categories of childcare were identified by the time at which children left the center-based care: "normal care" (use of center-based care for under 11 hours), and "extended care” (use of center-based care for 11 hours or more). Of the subjects, 125 (46.1\%) were enrolled in "normal care", and 146 (53.9\%) in “extended care”.

Family and child variables included the child's gender and age, child development along the Anme (2006) scale, the child rearing environment at home, the caregiver's efficacy for care, and the existence of childcare support. Professional caregivers measured child development along six variables (gross and fine motor, social competence, communication, vocabulary, and intelligence development) that were categorized into 2-point items [(normal, delayed) Anme, 2006]. These service providers in the center-based childcare facilities also evaluated the health and disabilities of the children based on descriptions by physicians.

The child rearing environment was assessed based on re- sponses (yes/no) to activities in the home environment (see Table 2). For analysis, the $25^{\text {th }}$ percentile point was used as a cut-off for non-nominal items. Caregivers' self reports on the five-point scale, (where 1 = always, 2 = often, 3 = sometimes, 4 = rarely, 5 = never) measured parental efficacy for care (Anme, 1998). The items used to assess the child's health at school age are believed to be reliable and valid and are consistent with those on the annual National School Health Survey by Japanese Ministry of Education.

\section{Results}

The difference between the two categories of care ("normal" and "extended") was examined by using items of child development, positive qualities of parents' behavior, parent efficacy for care, and existence of care support. The Statistical Analysis System (SAS) statistical package was used for analysis. Multiple

Table 2.

Number and percentage in risk group.

\begin{tabular}{|c|c|c|}
\hline items & No. & $\%$ \\
\hline \multicolumn{3}{|l|}{ 1) Child development } \\
\hline Gross motor & 10 & 3.7 \\
\hline Fine motor & 7 & 2.6 \\
\hline Social competence & 6 & 2.2 \\
\hline Communication & 3 & 1.1 \\
\hline Vocabulary & 7 & 2.6 \\
\hline Intellectual & 4 & 1.5 \\
\hline \multicolumn{3}{|l|}{ 2) Parent behavior } \\
\hline \multicolumn{3}{|l|}{ a) Human stimulation } \\
\hline Play with child & 8 & 3.0 \\
\hline Reading books & 43 & 15.9 \\
\hline Singing songs together & 18 & 6.6 \\
\hline At least one meal with parents & 3 & 1.1 \\
\hline \multicolumn{3}{|l|}{ b) Avoidance of restriction } \\
\hline Appropriate response to mistakes & 11 & 4.1 \\
\hline Punishment & 95 & 35.1 \\
\hline \multicolumn{3}{|l|}{ c) Social stimulation } \\
\hline Going to grocery store with parent & 7 & 2.6 \\
\hline Going to park with parent & 63 & 23.3 \\
\hline Going to friends' houses & 121 & 44.7 \\
\hline \multicolumn{3}{|l|}{ d) Support } \\
\hline Support for child care & 67 & 24.7 \\
\hline Having consultation & 16 & 5.9 \\
\hline Support from spouse & 33 & 12.2 \\
\hline Talking with spouse about child & 30 & 11.1 \\
\hline \multicolumn{3}{|l|}{ 3) View of child care } \\
\hline Confidence about child caring abilities & 17 & 6.3 \\
\hline \multicolumn{3}{|l|}{ 4) Adaptation for center based care } \\
\hline Adaptation for center based care & 5 & 1.9 \\
\hline
\end{tabular}


regression analysis was used to predict child health symptoms at school age (yes or no) with independent variables such as types of care ("extended care" or else), positive qualities of parents' behavior (13 items), parent efficacy for care, and existence of care support, child development (delayed or normal) and child adaptation to center-based care (adapted or not) at toddler age. An odds ratio was calculated to clarify the magnitude of effects. The odds ratio was calculated applying a multiple logistic analysis to estimate the strength of relations. All results were assessed significant at the $p<.01$ or $p<.05$ level, however, the variable "types of care" was not always selected as a related variable in all analyses.

Table 2 reports the number of risks in parent behavior.

Table 3 shows correlations with the child's health at school age. The maximum percentage is $17.0 \%$ for "easy to fatigue", while the minimum percentage is $7.8 \%$ for poor physical strength.

Table 4 reports the results of the Chi-square test between factors at the toddler age and the child's health at school age. The delay of fine motor at the toddler age was significantly related to anxiety at school age. Interestingly, being the only child was related being easily fatigued at school age.

Table 4 also presents the relationship between the caregiver's factors expressed when the child was a toddler and the child's health at school age. Not singing songs together in the early years was significantly related to poor physical strength at school age. Not going to the park with parents was related to headaches at school age.

As indicated in Table 5, a multiple regression analysis, that input all factors and excluded the effects of gender and grade in school, was employed to explain children's health at school age. Poor physical strength at school age was significantly related not playing with the child at the toddler age (odds ratio 3.23). Feelings of loneliness at school age was significantly related to not being adapted to center-based care at the toddler age (9.40).

\section{Discussion}

This is the first nation-wide study of center-based care that

Table 3.

Child's health at school age.

\begin{tabular}{lcc}
\hline \multicolumn{1}{c}{ Item } & Yes (\%) & No (\%) \\
\hline Feeling overwhelmed & 8.1 & 91.9 \\
Anxious & 11.4 & 88.6 \\
Get irritated & 15.1 & 84.9 \\
Poor physical strength & 7.8 & 92.2 \\
Easy to fatigue & 17.0 & 83.0 \\
Lonely & 11.4 & 88.6 \\
Displeasure and easy to get angry & 14.0 & 86.0 \\
Poor endurance & 13.7 & 86.3 \\
Headache & 10.7 & 89.3 \\
Feel depressed & 8.5 & 91.5 \\
Want to attack someone & 15.5 & 84.5 \\
Lose interest in study & 14.4 & 85.6 \\
& & $(\mathrm{n}=131)$ \\
\hline
\end{tabular}

focuses on the effects of extended-hour care, including night care, and that assesses child health at school age based on the complex relations among factors, including the quality of parent behavior. Center-based extended-hour care through midnight is unique in Japan, reflecting the increase in the number of parents who work late into the night. This investigation explored the influence of extended-hour center-based care (over 11 hours of care per day, including night care), in comparison to normal care (11 hours or less). All night care centers in this study had passed governmental standards and attempted to ensure that the natural circadian rhythms for children, such as sleeping, eating, and playing, were well maintained.

Several relatively recent large-scale, center-based childcare studies conducted outside Japan have documented relations between early and/or extensive childcare experience, noncompliance, and problem-behavior, even after controlling for selection effects (Bates et al., 1994; Baydar \& Brooks-Gunn, 1991; Belsky \& Eggebeen, 1991; Borge \& Melhuish, 1995; Park \& Honig, 1991; Vandell \& Corasaniti, 1990). Divergent results emerged from the current investigation, which found little evidence that the amount of time children spent in non-parental care in the first 2 or 3 years of life is, in and of itself, systematically related to children's self-control, compliance, or problem behavior by the time they reach the school-age years.

In light of prior studies and contemporary theory about the complex ecology of child development, the general absence of strong or consistent effects of the variable "type of care", by itself, may not be surprising. The compensatory-process, and lost-resource perspectives outlined in the introduction led to the anticipation of findings that highlight interactions between quality and quantity of care and child development more than main effects of the length of center-based care. Although quality was the most consistent predictor of child development, the amount of explained variance was modest, and standardized regression coefficients never exceeded .26 in the cumulativeexperience analysis and/or .16 in the lagged-and-concurrent analysis.

On the basis of analyses employed to identify selection-effect variables, several of the caregivers' and family characteristics that distinguished between families that participated in this study, and those who did not, may be systematically related to childcare quality. Nevertheless, the high rate of return and the highly homogeneous nature of Japanese society may minimize these effects. That the home environment was more strongly related to child development and adaptation than was length of center-based care is consistent with results of prior examinations of the effects of childcare on infant-mother attachment (NICHD, 1998b) and child development (Langlois \& Liben, 2003). The principal conclusion of this large-scale, multisite research project is that child rearing behavior by the caregiver may be more important in explaining children's health at school age than whether parents routinely use the services of high quality center-based care facilities or the length of time children spend in these facilities. Items strongly related to child health at school age, such as "playing with child" in infancy, may serve as a proxy items for a number of factors at home, because they indicate the opportunity to engage in activities inside and outside home, with other children, and in proximity of their caregivers.

Literature does suggest, however, that center-based care exerts some influence upon children. Studies report that the quality of care is the most consistent child-care predictor, with 
Table 4.

Factors related to child's health at school age.

\begin{tabular}{cccccc}
\hline & Category & Anxious \% & $\begin{array}{c}\text { Easy to fatigue } \\
\%\end{array}$ & $\begin{array}{c}\text { Poor physical } \\
\text { strength \% }\end{array}$ & Headache \% \\
\hline Child's factors at toddler age & & & & & \\
\multirow{2}{*}{ Fine motor } & Delay & $42.9^{*}$ & .0 & 14.3 & 14.3 \\
& Normal & 10.6 & 17.4 & 13.6 & 10.6 \\
\multicolumn{1}{c}{ Siblings } & No & 14.7 & $26.3^{* *}$ & 14.7 & 13.7 \\
& Yes & 9.7 & 11.9 & 13.1 & 9.1 \\
Caregiver's factors at toddler age & & & & & \\
\multirow{2}{*}{ Singing songs together } & No & 16.7 & 16.7 & $33.3^{*}$ & 16.7 \\
& Yes & 11.1 & 17.0 & 12.3 & 10.3 \\
Going to park with parents & No & 9.5 & 15.9 & 15.9 & $17.5^{*}$ \\
& Yes & 12.0 & 17.3 & 13.0 & 8.7 \\
\hline
\end{tabular}

Note: ${ }^{* *} p<.01 ;{ }^{*} p<.05$.

Table 5.

Odds ratio for child's health at school age.

\begin{tabular}{|c|c|c|c|c|}
\hline \multirow{2}{*}{ Item } & \multicolumn{2}{|c|}{ Poor physical strength } & \multicolumn{2}{|c|}{ Lonely } \\
\hline & Odds & Range & Odds & Range \\
\hline Gender & $2.79^{* *}$ & $1.29-6.01$ & $3.03^{*}$ & $1.29-7.11$ \\
\hline Grade in school & 1.09 & $.82-1.45$ & .99 & $.72-1.37$ \\
\hline Play with child & $3.23^{*}$ & $1.02-10.22$ & & \\
\hline Adaptation for center-based care & & & $9.40^{*}$ & $1.09-81.23$ \\
\hline Intercept & \multicolumn{2}{|c|}{-2.6523} & \multicolumn{2}{|c|}{-2.6979} \\
\hline H-L test & \multicolumn{2}{|c|}{.6836} & \multicolumn{2}{|c|}{.8609} \\
\hline
\end{tabular}

Note: ${ }^{* *} p<.01 ;{ }^{*} p<.05$.

higher quality of care relating to greater social competence and cooperation and less problem behavior at both two and three years of age (NICHD, 1998a). More time in low-quality care and more numerous care arrangements (i.e., less stable care) are predictors of negative outcomes for children at 2 years of age (NICHD, 1999b). Furthermore, greater experience in groups with other children predicted more cooperation and fewer problems at both 2 and 3 years of age.

While further follow-up research with the current sample will investigate less obvious effects of child-care that may emerge later in development, the findings of this study are believed to be useful in parent education programs. Outcomes of this study were integrated into practice as early childhood parent education programs highlighted the importance not only of the physical care of children but of increasing the quality of social interaction between parent and child.

\section{REFERENCES}

Ahnert, L., \& Lamb, M. E. (2003). Shared care: Establishing a balance between home and child care settings. Child Development, 74, 10441049. doi:10.1111/1467-8624.00587

Andersson, B. (1992). Effects of day care on cognitive and socio-emotional competence of thirteen-year-old Swedish schoolchildren. Child Development, 63, 20-36. doi:10.2307/1130898

Anme, T. (1991). Index of child care environment. Journal of National Rehabilitation Center for the Disabled, 12, 29-36.
Anme, T. (1995). Risk assessment using evaluation of environmental stimulation in Japan. National Roundtable on Child Protective Services Risk Assessment, 9, 37-47.

Anme, T., \& Segal U. (2004). Implications for the development of children placed in $11+$ hours of center-based care. Child: Care, Health and Development, 30, 345-352. doi:10.1111/j.1365-2214.2004.00429.x

Anme, T., \& Segal, U. (2003) Center-based evening child care: Implications for young children's development. Early Childhood Education Journal , 30, 137-143. doi:10.1023/A:1022005703976

Anme, T., Shinohara, R., Sugisawa, Y. et al. (2006). Development of standardized developmental scale for 0 - 7 child. Japanese Journal of Health and Welfare Statistics, 44, 346-352.

Anme, T., \& Takayama T. (1990). Evaluation of home stimulation for normal and handicapped children in Japan. In T. Takayama (Ed.), Early childhood toward the 21st century, (pp. 427-430). Hong Kong: Yew Chung Education Publishing Company.

Bates, J., Marvinney, D., Kelly, T., Dodge, K., Bennett, T., \& Pettit, G. (1994). Child-care history and kindergarten adjustment. Developmental Psychology, 30, 690-700. doi:10.1037/0012-1649.30.5.690

Baydar, N., \& Brooks-Gunn. (1991). Effects of maternal employment and child care arrangements on preschoolers' cognitive and behavioral outcomes: Evidence from the children of the National Longitudinal Survey of Youth. Developmental Psychology, 27, 932-945. doi:10.1037/0012-1649.27.6.932

Belsky, J., \& Eggebeen, D. (1991). Early and extensive maternal employment and young children's socioemotional development: Children of the National Longitudinal Survey of Youth. Journal of Marriage and Family, 53, 1083-1110. doi:10.2307/353011

Borge, A., \& Melhuish, E. (1995). A longitudinal study of childhood 
behavior problems, maternal employment, and day care in rural Norwegian community. International Journal of Behavioral Development, 18, 23-42.

Caldwell, B. M., \& Bradley, R. H. (1984). Home observation for measurement of the environment. Little Rock: University of Arkansas at Little Rock.

Crockenberg, S. C. (2002). Rescuing the baby from the bathwater: How gender and temperament (may) influence how child care affects child development. Child development, 74, 1034-1038. doi:10.1111/1467-8624.00585

Lamb, M. E. (1996). Effects of nonparental child care on child development: An update. Canadian Journal of Psychiatry, 41, 330-342.

Langlois, J. H. \& Liben, L. S. (2003). Child care research: An editorial perspective. Child Development, 74, 969-975. doi:10.1111/1467-8624.00581

Love, J. M., Harrison, L., Sagi-Schwartz, A., van Ijzendoorn, M. H., Rocc, C., \& Ungerer, J. (2003). Child care quality matters: How conclusions may vary with context. Child Development, 74, 1021-1033. doi:10.1111/1467-8624.00584

NICHD Early Child Care Research Network (1998a). The NICHD study of early child care. Psychiatric Times, 15, 71-72.

NICHD Early Child Care Research Network (1998b). Relations between family predictors and child outcomes: Are they weaker for children in child care? Developmental Psychology, 34, 1119-1128. doi:10.1037/0012-1649.34.5.1119

NICHD Early Child Care Research Network (1998c). Early child care and self-control, compliance and problem behavior at twenty-four and thirty-six months. Child Development, 69, 1145-1170.

NICHD Early Child Care Research Network (1999a). Child outcomes when child care center classes meet recommended standards for quality. American Journal of Public Health, 89, 1072-1077. doi:10.2105/AJPH.89.7.1072

NICHD Early Child Care Research Network (1999b). Child care and mother-child interaction in the first three years of life. Developmental Psychology, 35, 1399-1413. doi:10.1037/0012-1649.35.6.1399

NICHD Early Child Care Research Network (2001). Nonmaternal care and family factors in early development: An overview of the NICHD study of early child care. Journal of Applied Developmental Psychology, 22, 457-492. doi:10.1016/S0193-3973(01)00092-2

NICHD Early Child Care Research Network (2002a). Direct and indirect effects of child-care quality on young children's development. Psychological Science, 13, 199-206.

NICHD Early Child Care Research Network (2002b). The interaction of child care and family risk in relation to child development at 24 and 36 months. Applied Developmental Science, 6, 144-156. doi:10.1207/S1532480XADS0603 4

NICHD Early Child Care Research Network (2003). Does amount of time in child care predict socioemotional adjustment during the transition to kindergarten: Child Development, 74, 976-1005. doi:10.1111/1467-8624.00582

Park, K., \& Honig, A. (1991). Infant child care patterns and later teacher ratings of preschool behaviors. Early Child Development and Care, 68, 89-96. doi:10.1080/0300443910680108

Sacker, A., Schoon, I., \& Bartley, M. (2002). Social inequality in education achievement and psychosocial adjustment throughout childhood: Magnitude and mechanism. Social Science and Medicine, 55, 863-880. doi:10.1016/S0277-9536(01)00228-3

Salmela-Aro, K., \& Schoon, I. (2005). Human development and well-being. Special issue. European Psychologist, 10, 259-263. doi:10.1027/1016-9040.10.4.259

Schoon, I. (2006). Risk and resilience: Adaptations to changing times. Cambridge: Cambridge University Press. doi:10.1017/CBO9780511490132

Schoon, I., Bynner, J., Joshi, H., Parsons, S., Wiggins, R. D. \& Sacker, A. (2002). The influence of context, timing and duration of risk experiences for the passage from childhood to early adulthood. Child Development, 73, 1486-1504. doi:10.1111/1467-8624.00485

Vandell, D. L., \& Corasaniti, M. A. (1990). Child care and the family: Complex contributors to child development. New directions for child development, 49, 23-37. doi:10.1002/cd.23219904904

Watamura, S. E., Donzella, B. Alwin, J., \& Gunnar, M. R. (2003). Morning-to-afternoon increases in cortisol concentrations for infants and toddlers at child care: Age differences and behavioral correlates. Child Development, 74, 1006-1020. doi:10.1111/1467-8624.00583 